\section{Empirical and Experimental Constraints on Fe-Ti Oxide-Melt Titanium Isotope Fractionation Factors}

\author{
LIAM HOARE ${ }^{1}$, MARTIJN KLAVER ${ }^{1,2}$, DUNCAN MUIR ${ }^{1}$, \\ STEPHAN KLEMME ${ }^{2}$, JANE BARLING ${ }^{3}$, IAN \\ PARKINSON $^{4}$, JOHAN LISSENBERG ${ }^{1}$ AND MARC-ALBAN \\ MILLET $^{1}$ \\ ${ }^{1}$ Cardiff University \\ ${ }^{2}$ Universität Münster \\ ${ }^{3}$ Oxford University \\ ${ }^{4}$ University of Bristol \\ Presenting Author: hoare12@cardiff.ac.uk
}

Recent studies [1-3] have demonstrated the potency of titanium (Ti) isotopes as a tracer of Fe-Ti oxide-melt equilibria. Titanium primarily occupies a 5-fold coordination in silicate melts and 6-fold coordination in Fe-Ti oxides. This coordination contrast serves as the main mechanism driving $\mathrm{Ti}$ isotope fractionation, which results in a progressive enrichment in heavy $\mathrm{Ti}$ isotopes (expressed as high $\delta^{49 / 47} \mathrm{Ti}$ ) during magmatic differentiation. Additionally, the magnitude of $\mathrm{Ti}$ isotope fractionation observed during magmatic differentiation is controlled by melt $\mathrm{TiO}_{2}$ content and redox conditions, both of which influence the timing of Fe-Ti oxide crystallisation and the composition of Fe-Ti oxides [3].

Analyses of $\mathrm{Fe}-\mathrm{Ti}$ oxide mineral separates (titanomagnetite+ilmenite) [2] and ab-initio studies [4,5] have confirmed oxides are isotopically light compared to silicate melts or minerals. However, there is currently no data for individual oxide-melt $\mathrm{Ti}$ isotope fractionation factors.

We present $\mathrm{Ti}$ isotope fractionation factors for titanomagnetite, ilmenite and rutile, which have been derived from crystal-groundmass pairs in lavas from Santorini (calcalkaline) and Heard Island (intraplate), and from rutile-melt experiments [6]. Selected oxides and groundmass/glass were extracted via micro-mill for MC-ICP-MS analysis. Our results show that titanomagnetites display the largest mineral/melt $\Delta^{49 / 47} \mathrm{Ti}$ fractionation factors, followed by ilmenite, then rutile. This is consistent with stable isotope theory which dictates that lighter isotopes prefer longer bonds, with Ti-O bond length decreasing from magnetite to ilmenite and rutile. The titanomagnetite-melt fractionation factor also increases as a function of titanomagnetite $\mathrm{TiO}_{2}$ content, with magnetite from Heard Island $\left(>20 \mathrm{wt} \% \mathrm{TiO}_{2}\right.$ ) consistently displaying a greater fractionation factor in comparison to Santorini $\left(\leq 15 \mathrm{wt} \% \mathrm{TiO}_{2}\right)$. Our data enables the calculation of oxide-melt fractionation factors as a function of temperature, and $\mathrm{TiO}_{2}$ content in the case of titanomagnetite. We apply these fractionation factors to successfully reproduce the $\delta^{49 / 47} \mathrm{Ti}$ evolution of a series of differentiation suites [4] using Rayleigh modelling and constraints from mineral compositions and modal proportions in lavas from the aforementioned differentiation suites.

[1] Millet et al. (2016), EPSL. [2] Johnson et al. (2019), GCA. 